\title{
Global balance and the environment - Development feedback loop.
}

\author{
Grammenos Mastrojeni ${ }^{1,2, *}$ \\ ${ }^{1}$ Coordinator for the Environment and Head of the Science-Policy Interface, Italian Development Cooperation, Ministry of Foreign \\ Affairs \\ ${ }^{2}$ Professor of Environmental and Social Sustainability, LUMSA Pontifical University, Rome - and Tor Vergata Rome University
}

\begin{abstract}
Since developers have become more aware of the environment, policy-makers have noted a link between environmental and societal instability hinting at a human-nature planetary balance that hosts both stabilising retroactions and disruptive feedback loops: within the ecosystem, within society, and also connecting both dimensions. The commonly feared scenario is a "business as usual" neglect of natural balance, but the severe impairment of the ecosystem favours conditions worse than "business as usual". It would trigger human fragility, instability, and conflict which can paralyze society's ability to manage the ecosystem itself. This, in turn, could worsen environmental degradation, creating even greater instability and conflict in a dangerous self-feeding cycle. If verified, this understanding has deep operational implications and would ultimately require a revision of our economies. Policies are already being launched based on this perception, although it has not been investigated in rigorous quantitative terms: a call is out for science to fill the gap.
\end{abstract}

\section{Introduction}

A new era began for development in 2016, with a new agenda that sets World development course until 2030, building on the previous international framework, the Millennium Development Goals. This was a list of eight objectives, which led a more articulated architecture: 17 goals that specified 169 sub-targets (Figure 1) and subjected to monitoring through a set of quantitative indicators [1]. This set of actions is only the surface of a deeper revolution in perspective; the true novelty of the 2030 Development Agenda is that it reflects a new awareness about the world we live in: the need for global balance.

The 2030 Development Agenda is innovative by three main features:

- $\quad$ its development goals are qualified as sustainable,

it shifts the perspective of one-way aid - from the "rich" to the "poor" - to the horizon of a shared interest to better develop together; and, fundamentally.

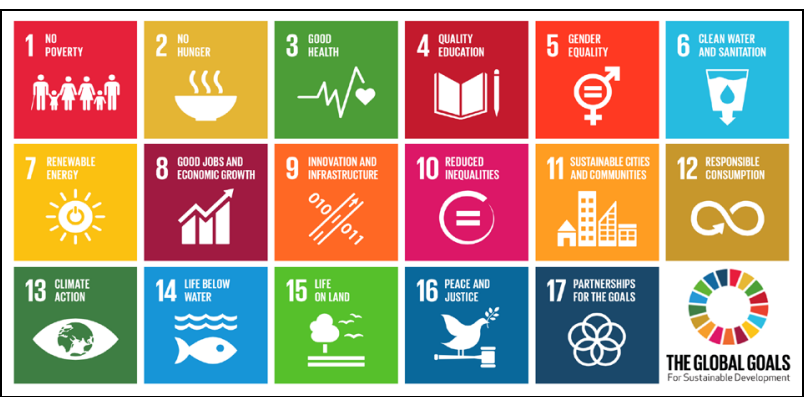

Fig. 1. Sustainable Development Goals[1]

\section{Understanding global balance: the "Earth's matrix"}

Humanity "vibrates" for achievements that "rhyme" with the ever growing change we call progress, expansion, growth. Instead, with few exceptions, we value balance as a viable condition but not as a goal, and it is in this sense, for instance, that balance is a concern in the economy [2]. We take balance for granted, especially when it refers to a stable and predictable ecosystem. Natural balance has mainly been preserved by the biosphere since the onset of the agricultural revolution, and we tended to take it for granted, not realising that without balance we cannot achieve growth or expansion - it is impossible to structure a stable society and progress without relying on natural cycles which are an expression of balance. Even worse, we tended to conceive balance as a static condition and therefore as inhibiting change, growth and progress. In this mindset, we saw the environment as a factor limiting wealth [3, 4], and felt that there was a trade-off that we had to come to terms with, sooner or later: since our planet's resources are finite, protecting environmental stability may well be a necessary burden in the end, but it can only come at the expenses of development. The 2030 Agenda, instead, implies that balance is not only compatible with progress and change, but also that there must be a dynamic balance between humankind and nature that acts as a propelling factor for expansion and quality of life: a synergy instead of a trade-off. 
The interactions harnessed within such planetary balance can be described, at various levels of complexity, in terms of a matrix, showing how the whole situation evolves as a result of the variation in its elements. Previous development agendas hinted in this direction: the images chosen to communicate both the Millennium Goals and the 2030 Agenda do look like a matrix, with similar graphics placing each goal in a box. In both tables, the difference between seeing them as a matrix, instead of a mere list of goals, consists of identifying the functions connecting the different boxes, which we are only starting to explore in quantitative terms. The fact that each of the 2030 Agenda goals will be monitored using quantitative indicators is not unrelated, just one step away from taking a path to monitor their interactions and grouped evolution.

If we look at the agendas in this perspective, we recognise functions that connect, for instance, "life on land" with "quality education" that, in turn, reflect on "no poverty" which, again, is a factor in "peace, justice, and strong institutions", the end result of which could, again in turn, reshape "life on land" and "quality education". In other words, we are coping with transsector local, regional, and even global feedback loops. Underlying the 2030 Agenda, a more organic table can describe global balance - from an anthropic point of view - as a dynamic relationship between the environment, development, human rights, and peace (Figure 2).

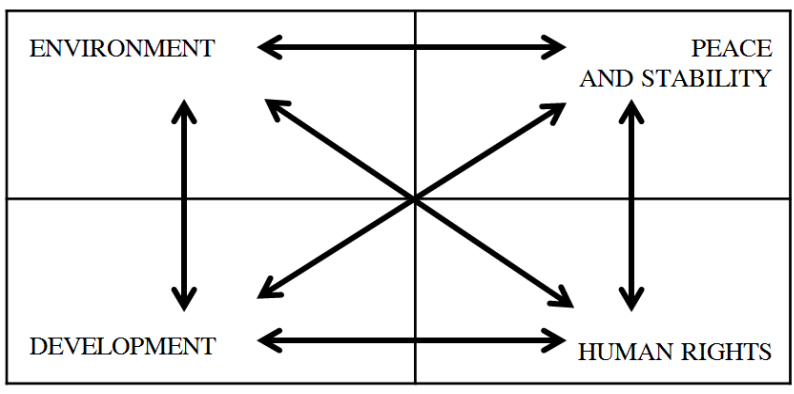

Fig. 2. An underlying balance matrix

\section{The threat of a mankind-nature system collapse}

There seems to be a feedback loop at work among the four dimensions: if land is contaminated, it will no longer sustain its owner, who can become vulnerable to abuses, prone to migration or easier prey for fanaticism. Conversely, if someone is granted a sounder education, they can manage better their farm, defend it from contamination, count on a more dignified livelihood, and therefore resist temptations to engage in conflicts, and so on. No matter which part of the matrix is subjected to initial stress or improvement, its consequences can cyclically reverberate on the three related dimensions and grow in scope and impact. Feed-back loops allow us to better understand and counter the local dynamics of coupled societal-environmental disruption. They have an explanatory and predictive power in local crises in which underdevelopment, the compression of rights, violence, and environmental decay seem trapped in an inextricable cycle where every stress factor seems to be both a cause and an effect $[5,6]$.

At this point in time, however, these dynamics look more than local and confined. We face "runaway climate change", the "great acceleration in species extinction", and "ocean acidification", among various scenarios of environmental collapse, which are themselves the product of the feed-back loops that humanity is triggering within the natural world. Even if these ecosystem-wide threats prove to be overestimated individually, global environmental unbalance is also a function of growing local and sectorial perturbations: more than the result of their sum, it mimics the product of their multiplication, because local or sectorial unbalances tend to fuse and trigger further unbalance [7, 8]. These trends would be problematic even if they only developed within the natural world, but the prospect is worse as they resonate, cross, and overlap with cycles of human instability. From the link between years of unprecedented drought and the Syrian crisis, to the role played by the agony of Lake Chad in fostering Boko Haram, all the way to the tensions around the shrinking Sea of Aral, disruptive human-environment loops are multiplying and converging.

Environmental degradation is often projected in future scenarios maintaining humanity as a rational or a non-reactive spectator, but the greatest unknown variable for the future is human behaviour in the context of a growingly dysfunctional ecosystem, not the ecosystem itself. If the impairment of ecosystem services becomes severe, it will trigger societal and institutional fragility, instability, and conflict which, in turn, will paralyze society's aptitude to rationally manage the ecosystem itself: predation of nature is a short-term way out in impoverished contexts [9]. This, in turn, could worsen environmental degradation, creating even greater instability and conflict, in a dangerous self-feeding cycle (Figure 3).

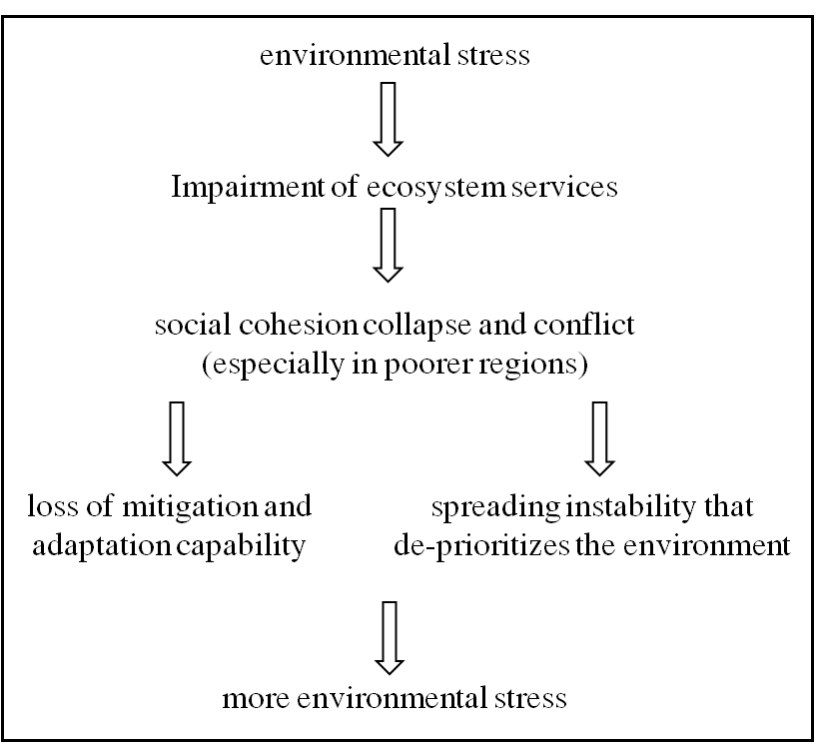

Fig. 3. Self-feeding cycle of environment stress [10-12] 
The need to break this cycle concerns all societies, but it is an absolute priority in developing regions [1315]. If adaptation fails there, hen these areas will opt out of the longer term strategic challenge of mitigation and global environmental recovery from the onset, to the detriment of everyone's interests $[16,17]$. At the same time, poorer communities are more likely to become hotspots of instability where human-environmental disruption cycles start, gain global momentum, and finally impact wider regions, dragging them into mitigation "paralysis" [18]. Development aid, from this perspective, acquires a new status: far beyond an instrument to bridge a gap in justice, it stands out as the first action needed to defuse a planet-wide loop of instability, provided it is environmentally compliant, integrated, and mainstreamed.

\section{Conclusions}

Feedback loops within the interconnectedness of the global system are threatening, and introduce a frightening degree of complexity: our task is not to solve a collection of isolated problems but to halt and reverse interlinked loops. But - once connection knots are identified - loops can provide a powerful amplifier to bring balance back on track, as we can leverage the interconnectedness in the opposite direction, towards rebalancing the system.

An imbalance in one sector tends to propagate to others and start cumulative cycles of instability, but the opposite also seems true: rebalancing crucial regions, sectors or dynamics could start a cascading cycle of wider rebalancing. This notion is surfacing at the operational level as we start to identify "co-benefits". Clearly, protecting biodiversity helps fight climate change, for instance; and even more promisingly, the societal co-benefits of environmental actions and the environmental co-benefits of socio-economic advances are emerging. In a circular balance system, the myth of the trade-off between nature and progress is dead.

Co-benefits are revealing feedback loops in a coherent global balance that can host both disruptive and constructive trans-sector cycles. The one feature that would make this balance coherent is "mixed" loops with both beneficial and destructive cascade consequences, among which a trade-off could be pondered - which seem to be foreign to the system: all dynamics tend to resolve either in a comprehensively constructive cycle or in its opposite, while mixed balances mostly characterise transition phases or, more often, are considered "progress" by a group of temporary "winners" to the detriment of "losers"; but the total sum remains negative for the system. It could suggest that what is fair and good for humanity as a whole tends to be protective of nature and, vice versa, that a healthy nature improves quality of life and encourages that more equitable development with which we are engaged in the 2030 agenda: no trade-offs.

Cyclical connections come with equivalences: fighting poverty means protecting the environment; involving women in building green belts improves security and economy; more justice in a region will propagate to other parts of the planet. The possible combinations are endless. This does not mean that we can avoid selecting priorities; the law of marginal utility tells us we should intervene first where the problem is more severe, such as poorer communities, or more fragile ecosystems that - this is not a coincidence - tend to overlap on the map.

A matrix is a mathematical architecture. It would not be surprising if its ultimate solution lies in a simple and elegant equation, like the one physics is struggling to find in a theory of everything. An equation for Earth's theory of all is emerging: environment $=$ justice.

\section{References}

1. United Nations. Transforming our world: the 2030 Agenda for Sustainable Development (2015)

2. W.N. Adger, Social and Ecological Resilience: Are They Related?, Progress in Human Geography, 24, 347-364 (2000)

3. K.W. Bultzer, Collapse, Environment and Society, Proceedings of the National Academy of Sciences USA, 109, 3632-3639 (2012)

4. A.B. Durning, Poverty and the Environment: Reversing the Downward Spiral, (WorldWatch Institute, Washington D.C., 1989)

5. B. Fagan, The Great Warming - Climate Change and the Rise and Fall of Civilizations (Bloomsbury, New York, 2009)

6. W.A. Fox, M. Renner, A.H. Westing, Environmental Degradation as Both a Consequence and Cause of Armed Conflict, Environmental Awareness, 25/1, 5 (2002)

7. H. Gee. Treeless at Easter, Nature, (7007) 443-6 (September 23, 2004)

8. T.F. Homer Dixon, 1999. Environment, Scarcity, and Violence, (Princeton University Press, Princeton, 1999)

9. S.M. Hsiang, K.C. Meng, M.A. Cane, Civil Conflicts Are Associated with the Global Climate, Nature, 477, 438-441 (2011)

10. International Organization for Migration (IOM), The Relationship between Environmentally-Induced Population Displacements and Environmental Impacts, (1996 Geneva)

11. S. Mason, A. Muller, A. Schnabel, C. Schmid, Linking Environment and Conflict Prevention: The Role of the United Nations, (Center for Security Studies, ETH, Zurich, 2008)

12. G. Mastrojeni, The Climate Challenge and the Value of Our Lands, Review of Environment, Energy and Economics (Re3), (November 2015)

13. J.W. Mellor, J.W., The Intertwining of Environmental Problems and Poverty, Environment, 30/9, 8-30 (1998)

14. C. Perrings, An Optimal Path to Extintion? Poverty and Resource Degradation in the Open Agrarian Economy, Journal of Development Economics, 30, 1-24 (1989) 
15. M. Renner, Fighting for Survival. Environmental Decline, Social Conflict, and the New Age of Insecurity, (Norton, New York, 1996).

16. Human Development Report 2011 - Sustainability and Equity: A Better Future for All (UNDP, New York, 2011).

17. From Conflict to Peacebuilding: The Role of Natural Resources and the Environment (UNEP, Nairobi, 2009).

18. D.D. Zhang, P. Brecke, H.F. Lee, Y-Q. He, J. Zhang, J., Global Climate Change, War, and Population Decline in Recent Human History, Proceedings of the National Academy of Sciences USA, 104(49), 19214-19219 (2007) 